\title{
TRIP STEEL SPECIMEN PREPARATION FOR ADVANCED SEM AND EBSD
}

\author{
1Ondřej AMBROŽ, 2Šárka MIKMEKOVÁ, ${ }^{3}$ Veronika HEGROVÁ, ${ }^{4}$ Tomohiro AOYAMA \\ 1'Institute of Scientific Instruments of the CAS, Brno, Czech Republic, EU, ondrei@isibrno.cz \\ 2Institute of Scientific Instruments of the CAS, Brno, Czech Republic, EU, sarka@isibrno.cz \\ ${ }^{3}$ NenoVision s.r.o., Brno, Czech Republic, EU, veronika.hegrova@nenovision.com \\ 4JFE Steel Research Laboratory, JFE Steel Corporation, Fukuyama, Japan, to-aoyama@ife-steel.co.jp
}

https://doi.org/10.37904/metal.2020.3513

\begin{abstract}
Modern scanning electron microscopy (SEM) allows observations of specimens with high surface sensitivity. The surface sensitivity is significantly affected by the accelerating voltages. With the development of the scanning electron microscopy, the requirements for the surface quality of samples increase. Metallographic methods originally intended for light microscopy become insufficient. The problem occurs especially with multiphase materials having a fine-grained structure. The investigated TRIP steel consists of a ferritic-bainitic matrix, retained austenite and martensite phases. The sizes of the smallest phases are nanometer units. The volume of residual austenite was determined by X-ray diffraction. The basic preparation of all tested samples involved conventional metallographic grinding and very fine mechanical polishing. One sample was analysed in this state. Other samples were subsequently chemically polished, electropolished and chemicalmechanically polished. The specimens were observed in the SEM using a SE and a BSE detector at low energies immediately after the preparation. An EBSD was performed in the same areas to characterize the retained austenite. Topographical imaging by special AFM, integrated into the SEM, demonstrated that the mechanical polishing results in surface deformation and residual austenite is transformed. All other methods have their specifics and for modern sensitive SEM instruments it is necessary to optimize individual procedures.
\end{abstract}

Keywords: TRIP steel, metallography, SEM, EBSD, AFM

\section{INTRODUCTION}

Multiphase steels, including TRIP steels, excel in their mechanical properties and find application in many sectors, such as the automotive industry. The uniqueness of these steels is mainly due to their multiphase internal structure, which allows us to obtain a suitable combination of different properties, such as achieving high strength and good ductility. Studying the microstructure of such materials is very difficult, especially concerning the differentiation of phases. The microstructure of this steel is usually composed of ferrite (50-60 vol.\%), bainite (25-40 vol.\%), residual austenite, and martensite [1]. The essence of the processes in strengthening TRIP steels is the phase martensitic transformation, which is stress assisted or strain-induced. Austenite regions take over the load under the action of external stress and transform it into martensite, which is further deformed. The deformation of martensite is homogeneous in the temperature range Ms and Md. This means that it is not concentrated in a certain area, but is evenly distributed throughout the volume [2]. The popularity of scanning electron microscopy in metallography is based on the substantial progress made by the developers of SEM instruments in recent years. There are several advantages such as high resolution, large depth of field, and a wide magnification range. The surface sensitivity of the modern scanning electron microscopes has high demands on sample preparation. It is necessary to prepare a sample without deformations and significant topography. Sample preparation for an electron back-scattered diffraction (EBSD) 
is considerably more difficult than for conventional SEM due to the very low penetration depth of the primary electrons. It ranges from 20 to $370 \mathrm{~nm}$ (depending on the material). Chemical etching is not generally recommended for the EBSD characterization because of the rough surface topography, which is very disruptive after the specimen tilt. A thin deformed layer after mechanical polishing prevents the acquisition of good quality patterns and therefore the preparation must be improved [3]. This applies, particularly to the final polishing step. A chemical-mechanical polishing (silica) with longer times is often the last step of polishing. It is also advisable to reduce the rotation speed of the polishing machine and to reduce the pressing force to a minimum. Electropolishing is often the last step in the preparation of TRIP steels.

The present paper shows the effect of the last polishing step on the Fe-0.17C-1.5Si-1.7Mn TRIP steel surface condition. The TRIP steel specimens prepared in various ways were imaged in SEM and the EBSD and atomic force microscopy (AFM) techniques were used as complementary imaging techniques.

\section{EXPERIMENTAL TECHNIQUES}

The retained austenite content was determined by an X-ray diffraction to $12.1 \%$. The $1 \mathrm{~mm}$ thick sheet of the examined material was cut into square samples of $9 \mathrm{~mm}$ side length. These samples were mounted in resin. The surface of samples was mechanically grinded and polished in several steps (Table 1).

Table 1 Grinding and mechanical polishing parameters

\begin{tabular}{|c|c|c|c|c|c|}
\hline Medium & $\begin{array}{c}\text { Speed } \\
(\mathrm{rpm})\end{array}$ & $\begin{array}{l}\text { Time } \\
(\min )\end{array}$ & $\begin{array}{l}\text { Load } \\
\text { (N) }\end{array}$ & Rotation & Cooling \\
\hline 220 diamond disc & 300 & 3 & 35 & $\mathrm{co}$ & water \\
\hline 500 diamond disc & 300 & 3 & 30 & co & water \\
\hline 1200 diamond disc & 300 & 5 & 25 & $\mathrm{co}$ & water \\
\hline $9 \mu \mathrm{m}$ diamond suspension & 140 & 5 & 25 & $\mathrm{co}$ & water basec \\
\hline $3 \mu \mathrm{m}$ diamond paste & 130 & 3 & 20 & $\mathrm{co}$ & isopropanol \\
\hline $1 \mu \mathrm{m}$ diamond paste & 130 & 3 & 15 & $\mathrm{co}$ & isopropanol \\
\hline $0.25 \mu \mathrm{m}$ diamond paste & 130 & 10 & 10 & co & isopropanol \\
\hline
\end{tabular}

After mechanical polishing, the specimens were polished chemical-mechanically, chemically and electrolytically. One sample was observed only after mechanical polishing (Table 2).

Table 2 Final polishing methods

\begin{tabular}{|c|c|c|}
\hline Sample & Time & Solution \\
\hline a) mechanical polishing & $10 \mathrm{~min}$ & $0.25 \mu \mathrm{m}$ diamond paste, isopropanol \\
\hline b) chemical-mechanical polishing & $3 \mathrm{~h}$ & $40 \mathrm{~nm} \mathrm{SiO} 2$ particles, pH 9.8, $60 \mathrm{rpm}, 5 \mathrm{~N}$, counter \\
\hline c) electropolishing & $4 \mathrm{~s}$ & $50 \mathrm{ml}$ perchloric acid, $950 \mathrm{ml}$ acetic acid, $40 \mathrm{~V}, 15^{\circ} \mathrm{C}$ \\
\hline d) chemical polishing & $10 \mathrm{~s}$ & $5 \mathrm{ml} \mathrm{HF}, 95 \mathrm{ml} \mathrm{H}_{2} \mathrm{O}_{2}$ \\
\hline
\end{tabular}

Chemical-mechanical polishing uses nano-sized oxide polishing suspensions to remove the last deformations. One sample was polished with colloidal silica suspension in our experiment for 3 hours. The removal of material occurs due to the combination of the chemical reaction of the suspension with the sample surface and the continuous removal of the reaction products by the abrasive. The sample surface is often slightly attacked after this process and particles settle on the surface, but the process produces scratch-free and deformation-free layers [4]. 
Another sample was prepared by electropolishing. Electropolishing conditions can be optimized in such a way that the surface is smoothed by removing any irregularities above $1 \mu \mathrm{m}$. This is followed by surface brightening, which is caused by the removal of all submicron irregularities up to approximately $0.01 \mu \mathrm{m}$. Electropolishing can completely remove the deform layer from mechanical grinding and polishing operations used in specimen preparation [3]. A solution of $50 \mathrm{ml}$ perchloric acid and $950 \mathrm{ml}$ acetic acid $\left(40 \mathrm{~V}, 4 \mathrm{~s}, 15^{\circ} \mathrm{C}\right)$ was used. The individual phases differ in their electrode potential and thus each phase also has different corrosion resistance. Different phases dissolve at different rates during the process.

One sample was chemically polished. Chemical polishing is a process for obtaining the final surface by immersion in a suitable solution. It is a controlled corrosion process with many similarities to electropolishing. The polishing was made by immersing the specimen into the $5 \% \mathrm{HF}$ in $\mathrm{H}_{2} \mathrm{O}_{2}$ for $10 \mathrm{~s}$.

Samples were observed in a DualBeam FIB-SEM Helios G4 HP (Thermofisher Scientific) to obtain SE and BSE images immediately after preparation. The microscope was set at $1 \mathrm{kV}$ accelerating voltage, $0.8 \mathrm{nA}$ probe current, and the working distance of $7 \mathrm{~mm}$. EBSD data were subsequently acquired from a Magellan $400 \mathrm{~L}$ SEM microscope (Thermofisher Scientific) equipped with an EBSD detector with Ametek-EDAX TEAM software at $20 \mathrm{kV}, 1.6 \mathrm{nA}$, WD $9 \mathrm{~mm}$ and a step size of $70 \mathrm{~nm}$. True topography of the sample surface was observed by unique AFM LiteScope ${ }^{\mathrm{TM}}$ (NenoVision) integrated into SEM. The AFM-SEM connection enabled facile identification of the region of interest and simultaneous acquisition of surface morphology and material contrast.

\section{RESULTS AND DISCUSSION}

The true morphology of the surface condition after chemical-mechanical polishing, chemical polishing and electropolishing is represented by AFM images (Figure 1). The smoothest surface was achieved chemicalmechanical polishing. We can see the path of the abrasive particles and no secondary phases. The largest height difference between the individual phases is evident from chemical polishing. Austenite was etched to the greatest depth. Electropolishing is characterized by a slightly corrugated surface. There is no significant height difference between phases.
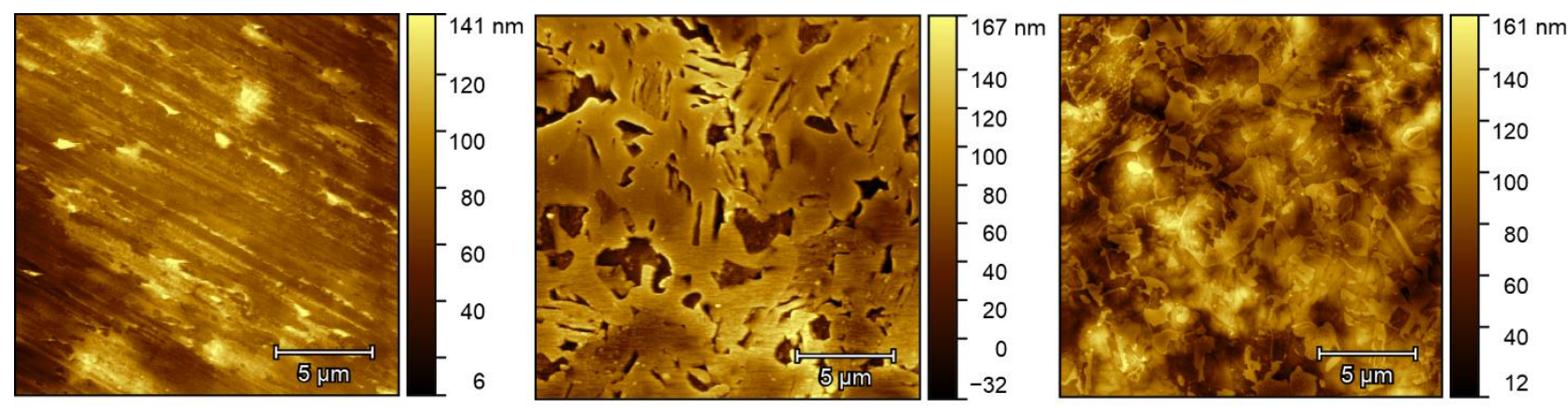

Figure 1 True surface morphology by AFM topography imaging: TRIP steel surface finished by chemicalmechanical polishing, chemical polishing and electropolishing technique (from the left)

Several metallographic techniques were used to prepare samples of TRIP steel and their SEM micrographs are shown in Figure 2. The surface of the samples was imaged on the impact energy of the primary beam of $1 \mathrm{keV}$, which guarantees very high surface sensitivity. Higher surface sensitivity is evident in the images taken by the in-lens SE detector, while the images taken by the BSE detector exhibit material contrast.

The first sample represents only a mechanically polished surface and, as can be seen, the secondary phases are not visible. The EBSD results show that the surface was deformed after mechanical polishing. All retained austenite was transformed into the martensite phase. In the case of chemical-mechanical polishing, one can observe a slight attack of the surface in the SE image. Contamination by colloidal silica is evident in the BSE 
image. It is a common phenomenon observable in this method of sample preparation. The number of these particles adhered to the sample is supported by the long polishing time. Very fine phases of retained austenite can be detected in the EBSD phase map. In the SE and the BSE images of the chemically polishing specimen, one can distinguish the secondary phases due to their selective etching. The EBSD phase map demonstrates that the areas of retained austenite are traceable, but not to a greater extent. The image quality is worse than in the case of electropolishing and chemical-mechanical polishing, as demonstrated by the EBSD confidence index $(\mathrm{Cl})$ map. The middle way between those methods illustrates the results of electropolishing. The SEM images show that the ferrite matrix is equally etched and the secondary phases can be distinguished, as in the case of chemical polishing, but the surface quality is better. This confirms the proportion of retained austenite.

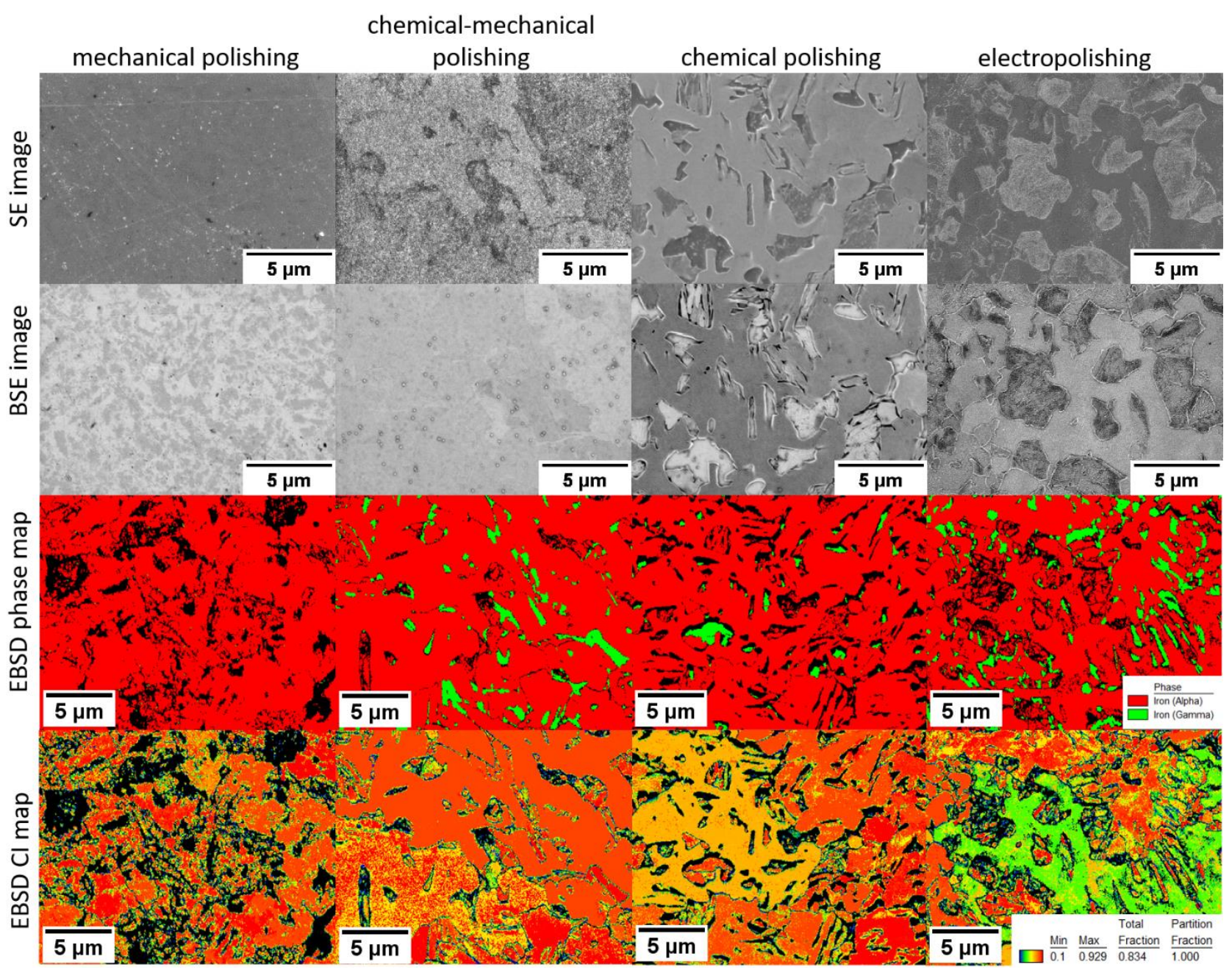

Figure 2 SE and BSE micrographs of the specimens prepared by various metallographic techniques, together with corresponding EBSD maps (phase map, confidence index map)

\section{CONCLUSION}

In the present study, metallographic methods for the preparation of the TRIP steel samples are described. The sample preparation is crucial in order to obtain high-quality information about the phase composition of the examined material. The surface layer is deformed after mechanical polishing. Detection of retained austenite is impossible. Chemical-mechanical polishing with longer polishing times creates a very smooth surface, as confirmed by AFM topography, and suitable for the EBSD analysis. However, the surface is contaminated and the individual phases cannot be identified in SEM images. Chemical polishing is promising for the characterization of individual phases in SEM, but the process must be optimized in order to obtain reasonable 
quality EBSD data. The electropolishing technique is suitable for the EBSD analysis but separation between austenite and martensite phases in SEM images is not possible.

\section{ACKNOWLEDGEMENTS}

The research was supported by Technology Agency of the Czech Republic (TN01000008).

\section{REFERENCES}

[1] LEHMHUS, D., BUSSE, M., HERRMANN, A.S., KAYVANTASH, K., ed. Structural Materials and Processes in Transportation [online]. Weinheim, Germany: Wiley-VCH Verlag GmbH \& Co., 2013 [cit. 2020-05-06]. Available from: DOI: 10.1002/9783527649846.

[2] FREMUNT, P., PODRÁBSKÝ, T. Konstrukční oceli. Brno: CERM, 1996.

[3] GEELS, K. Metallographic and materialographic specimen preparation, light microscopy, image analysis and hardness testing. West Conshohocken: ASTM International, 2007.

[4] SAMUELS, L.E. Metallographic polishing by mechanical methods. 4. Materials Park: ASM International, 2003. 